EESTI NSV TEADUSTE AKADEEMIA TOIMETISED. $X$ KÖIDE

FOOSIKALIS-MATEMAATILISTE JA TEHNILISTE TEADUSTE SEERIA, 1961, NR. 4

ИЗВЕСТИЯ АКАДЕМИИ НАУК ЭСТОНСКОК ССР. ТОМ Х

СЕРНЯ ФИЗИКО-МАТЕМАТИЧЕСКИХ Н ТЕХННЧЕСКИХ НАУК. 1961, № 4

\title{
KIRDE-EESTI ALUSKORRA JA ALUSPÖHJA STRUKTUURIDE DETAILNE UURIMINE GRAVIMEETRILISE MEETODIGA
}

\author{
V. MAASIK, \\ fūüsikalis-matemaatiliste teaduste kandidaat
}

Eesti NSV Teaduste Akadeemia Geoloogia Instituudis aastatel 1952-1960 saadud regionaalsete ja lokaalsete gravitatiivsete anomaaliate interpretatsiooni tulemused koos teiste geofüüsikaliste uurimiste resultaatidega võimaldasid koostada Eesti NSV territooriumi kristalse aluskorra gravitatiivsete struktuuride kaardi ja skemaatilise struktuurgeoloogilise kaardi mōôdus 1:2500000 (vt. kaardid 1 ja 2).

Nende kaartide ja puuraukude andmeil koosneb kristalne aluskord Põhja-Eestis põhiliselt kergetest moondekivimitest. Kulutatud ürgsete mäesüsteemide alad on siin pangasteks lōhutud, mis üksteise suhtes on vertikaalsuunas nihkunud ja on väga erineva vanuse ning suurusega intrusioonidest injitseeritud.

Seoses rabakivi intrusioonidega Viiburi, Ahvenamaa jt. piirkondades toimusid ümbruskonna kivimeis tugevad purustused $\left[{ }^{13}\right]$. Uks tollal tekkinud tektooniliste rikete vöönd, mis kulgeb piki Soome lahe lounarannikut, etendas nähtavasti olulist osa Põhja-Eesti paekalda kujunemisel. Kirde-Eesti lokaalsete gravitatiivsete struktuuride vöönd (Uljaste Sillamäe - Narva-Jōesuu) arvatavasti markeerib selle rikkevööndi lõunaosa. Tema lokaalseid gravitatiivseid struktuure pōhjustavad suured aluselised intrusioonid, mis ei jōudnud tungida tolleaegse kristalse aluskorra pealispinnani, vaid jäid peatuma sügavamale kris talsesse aluskorda. Tugev denudatsioon enne settekivimite kompleksi tekkimist tõi nad pealispinnale lähemale. Selles piirkonnas on kristalse aluskorra kivimid märgatavalt lōhestunud ja piirkond tervikuna on tektooniliselt aktiivsem kui ümbruskond

Oks selle piirkonna intrusioonidest paikneb-Kabala-Sonda vahelisel maa-alal. Gravimeetriliste andmete järgi kujutab see nn. Uljaste intrusioon endast peaaegu vertikaaiset elliptilist silindrit, mille horisontaallōike poolteljed on 2 ja $1,5 \mathrm{~km}$ pikad; silindri pikkus on ca $8 \mathrm{~km}$. Sillamäe ja Narva-Jōesuu lokaalsete struktuuride olemasolu on tõestatud, kuid nende mōōtmeid pole võimalik määrata selle tōttu, et nad jätkuvad Soome lahe alale, kus gravitatiivset välja pole veel jōutud uurida.

Eespool mainitud lokaalsete gravitatiivsete struktuuride vööndil on kristalse aluskorra kivimid suurema tihedusega kui rikkumata alal. Lähtudes selle struktuuri massi ekstsessist ja môningate puursüdamike [ $\left.{ }^{[}\right]$uurimisel saadud tiheduse andmeist, võime siinse kivimite kompleksi keskmiseks tiheduseks arvestada $2,90-3,03 \mathrm{~g} / \mathrm{cm}^{3}$. Kivimid on tugevasti metamorfiseerunud. Esineb koos nii raskemaid kui ka kergemaid kivimeid, nagu (sulgudes tihedus $\left.\mathrm{g} / \mathrm{cm}^{3}\right)$ : amfiboolskarn $(3,19-3,89)$, magnetiitkvartsiit $(3,52)$, pürokseengneiss $(3,34)$, pürokseenskarn $(2,95-3,40)$, granaatskarn $(3,22)$, gneiss pegmatiidiga $(3,03-3,23)$, gneiss $(2,88-3,34)$, amfiboolgneiss $(2,98-3,30)$, pegmatiit $(2,58-2,73)$ jne. Kohati esineb aluselisi ja ultraaluselisi kivimeid ja nendega kaasnevad maagid ja maagistumisvööndid.

Uljaste-Sillamäe-Narva-Jõesuu lokaalsete positiivsete gravitatiivsete struktuuride vöğndit märgivad ka magnetilised anomaaliad. ${ }^{1}$

Gravimeetriline meetod ei vōimalda määrata lokaalsetele gravitatiivsetele struktuuridele vastavate intrusioonide vanust. Oletades tekkelist sidet nende ja rabakivi intrusioo-

1 Töid teostas Balti Aeromagnetomeetriline Rühm nr. 35/59. 
nide vahel, peaksid nad olema tekkinud kambriumieelsel ajal. Ent Kirde-Eesti rikkevöönd jäi väga pikaks ajaks tektooniliselt aktiivseks ning etendas tähtsat osa siinse aluskorra ja aluspöhja geoloogilise ehituse kujunemisel, eriti siinsete maagistumispiirkondade ja dolomiidistumisvööndite väljakujunemisel.

Vaatame, kuidas on eespool saadud gravitatiivsete struktuuride geoloogilise tōlgendamise tulemus kooskōlas meie ala ja ümbruskonna kristalse aluskorra ehitusega ning kas vōis kambriumieelse aluskorra kivimite massiivides areneda intrusioonide tegevus.

Kahjuks on otsesed andmed Eesti kambriumieelse aluskorra ehitusest küllaltki napid. Aluskorra kivimilist koosseisu on võidud jälgida ainult vähestes puuraukudes. Neist andmeist ei piisa meie kristalse aluskorra ehituse isegi kōige pealiskaudsemaks iseloomustamiseks. Sellepärast tuleb geofüüsikaliste andmete geoloogiliseks interpretatsiooniks kasutada ka neid kogemusi ja teadmisi, mida on saadud naberalade kambriumieelse aluskorra uurimisel. Esmajärjekorras mōtleme siin naaberriigi Soome territooriumi, mida meie alast lahutab ainult 50-120 kilomeetri laiune Soome laht ja kus kambriumieelse aluskorra kivimid paljanduvad.

Eesti NSV territooriumi geoloogilise interpretatsiooni puhul oleme kasutanud P. Eskola [1], S. Kaitaro $\left[{ }^{3}\right]$, A. Laitakari $\left[{ }^{4}\right]$, M. Saksela $\left[{ }^{10}\right]$, J. Sederholmi $\left[{ }^{11}\right]$, H. Tuomineni $\left.{ }^{[12}\right]$ jt. töödes avaldatud andmeid.

Olles 15 aastat uurinud Eesti ala gravimeetrilist välja ja vastavaid struktuure ning vōrrelnud neid Soome territooriumilt saadud gravimeetriliste, ja geoloogiliste uurimiste tulemustega, on autor jõudnud veendumusele, et Eesti ala kambriumieelsest aluskorrast kuulub valdav osa Svekofenniidide kurrutussüsteemi. Seega on autor jōudnud samale tulemusele, mille esimesena avaldas A. Opik juba 1936, a. $\left[{ }^{14}\right]$. Tundes selle kurrutussüsteemi geoloogilist ehitust ja arvestades gravimeetriliste ning teiste geofüüsikaliste mōōdistamiste tulemusi, saab täpsustada Eesti ala, eriti Pổha-Eesti kambriumieelse aluskorra geoloogilist ehitust. Oppinud tundma Svekofenniidide kurrutussüsteeme Lōuna-Soomes, saame vastuse oma küsimusele, kas Eesti ala arhailistes ja proterosoilistes massiivides võis areneda hilisem intrusiivne tegevus.

Ammendava vastuse sellele küsimusele saame soome geoloogide ja geofüüsikute töödest.

H. Tuomineni $\left[{ }^{12}\right]$ järgi tekkisid Svekofenniidid 1 kuni 1,2 miljardit aastat tagasi. Järelikult on nad juba ammu denudeerunud ja ära kantud. Säilinud on vaid kurrutussüsteemi «juured». Osake Svekofenniidide kurrutussüsteemist on säilinud Lōuna-Soomes Helsingist läänes. Neid säilinud osi uuris hoolega $H$. Tuominen magnetomeetrilise ja elektromagnetomeetrilise meetodiga. Ta môōtis $990 \mathrm{~km}^{2}(45 \times 22 \mathrm{~km})$ suurusel maa-alal magnetomeetriliselt 0,5 miljonit ja elektromagnetomeetriliselt 200000 punkti. Mōōdistamise interpreteerimine näitas, et vanade Svekofenniidide jäänused kannavad tugevaid kurrutuse jälgi, mis on tingitud intensiivsetest tektoonilistest protsessidest. Lõhede süsteemid, mis avastati geofüüsikaliste anomaaliate kaudu, suunduvad nii paralleelselt kui ka risti kurrutuse üldsuunale.

Meie territooriumil taolisi töid ei ole tehtud.

H. Tuomineni uurimustest järeldub, et Svekofenniidide kurrutussüsteemi tekkimine oli seotud suurte lōhestumistega ja et maakoore plastilisus tol ajal ei erinenud märgatavalt praegusaegsest plastilisusest.

Siit vôime järeldada, et ka Eesti territooriumi kambriumieelset aluskorda läbivad kunagised arhailised ja proterosoilised purustusvööndid, lōhed ja intrusioonid, mida fikseerivad gravitatiivsed ja teised geofüüsikalised anomaaliad. Seega eeldavad soome geoloogide ja geofüüsikute uurimiste tulemused ka Kirde-Eesti rikkevööndi olemasolu, mis etendas tähtsat osa siinse aluspōhja ja aluskorra ehituse muutustes, eriti siinsefe maagistumispiirkondade ja vööndite väljakujunemisel.

Sellest seisukohàst läbtudes tulebki suunata geofüüsikalisi töid Eesti ala kambritumieelse aluskorra ja aluspōhja uurimisel, eriti nende ehituse täpsustamisel. Kerkivad päevakorda vähemate tektooniliste rikete, sealhulgas kirdesuunaliste rikete olemuse ja tekkepōhjuste uurimine. 


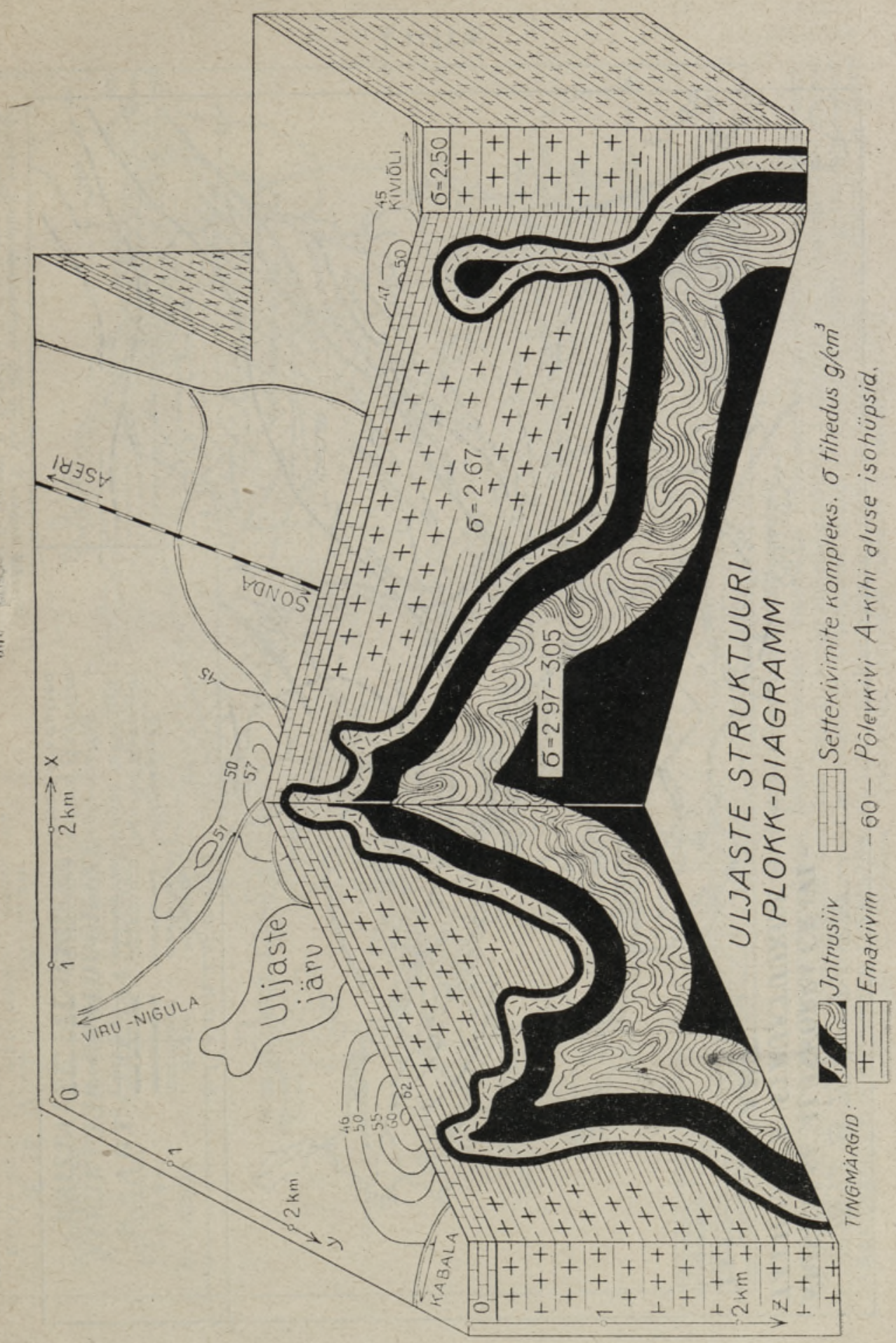


$\mathrm{Ka}$ a $\mathrm{rt} 1$.

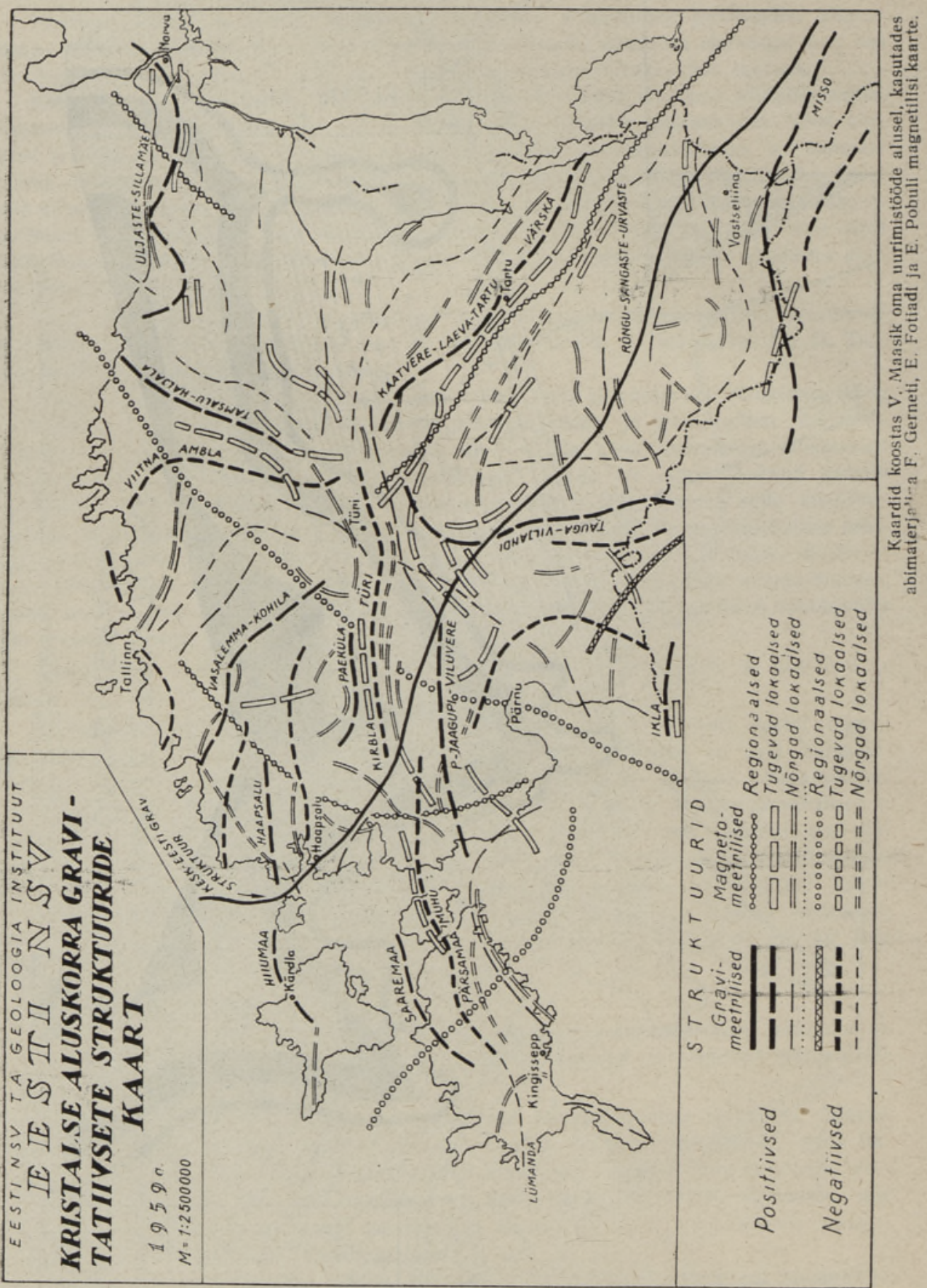


$\mathrm{Ka}$ art 2

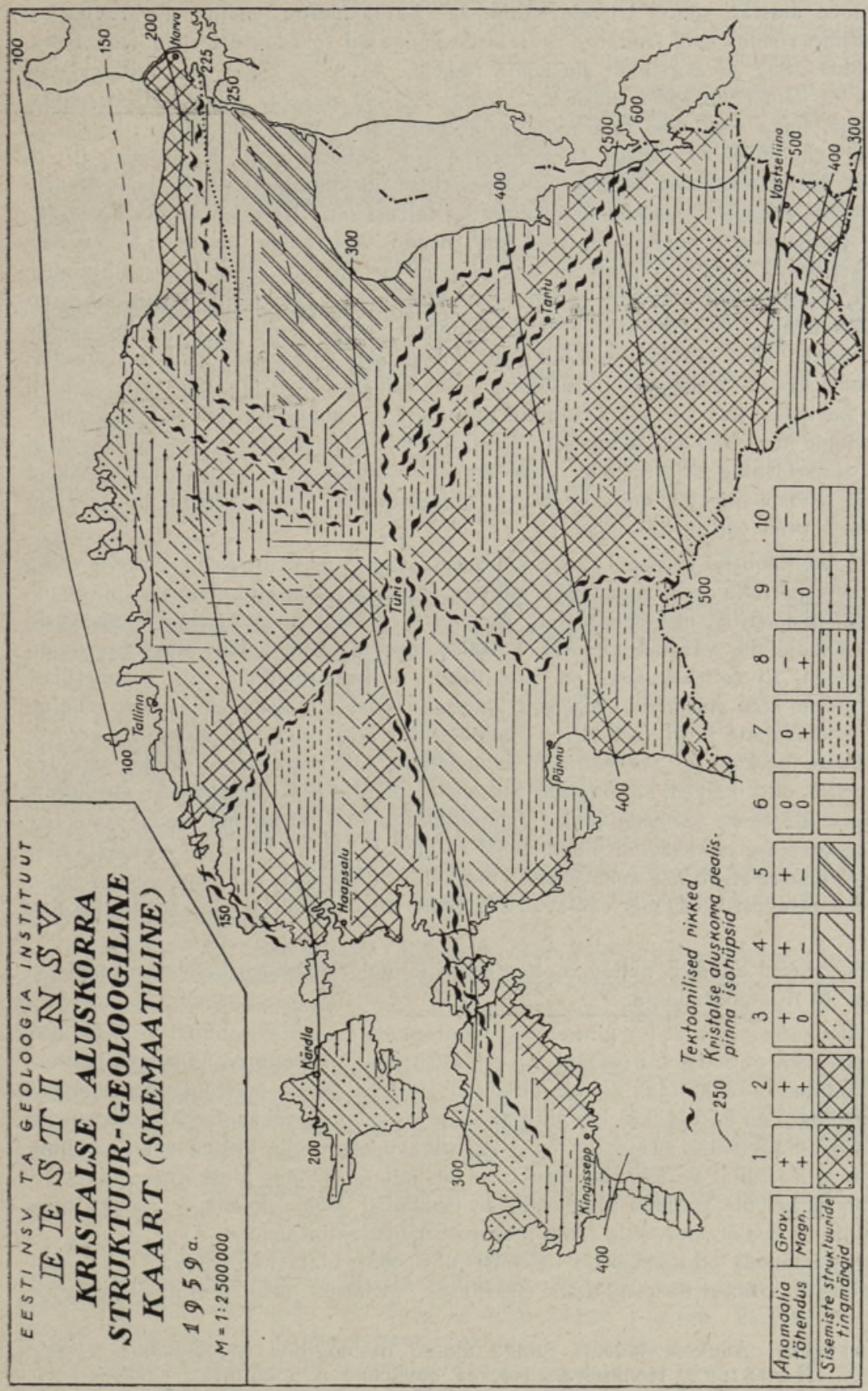

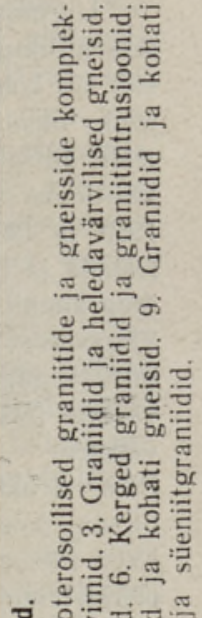

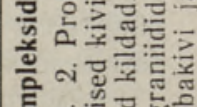

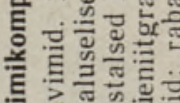

竞:

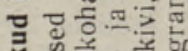

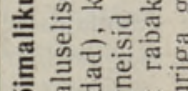

i⿱宀

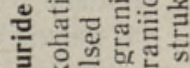

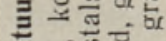

क音

늘

틍명폴

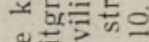

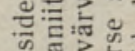

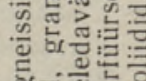

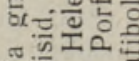

……

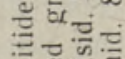

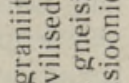

需国

氜可

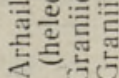

$-\therefore$ 
Sel eesmärgil uuriti Kirde-Eestit 1959. ja 1960. aasta suvel gravimeetriliselt detailselt ja suure täpsusega. See töö on vahetuks jätkuks samas teostatud üldgravimeetrilistele uurimistööđlele.

Uurimistööd alustati suurel Uljaste-Sillamäe-Narva-Jōesuu positiivsete gravitatiivsete struktuuride vööndi neis kohtades, kus kirdesuunalised lōhede süsteemid teda lôikasid, või kohtades, kus oli avastatud aluspōhja rikkeid. Autor oletas, et neis piirkondades peaks olema ka kambriumieelses aluskorras mingisuguseid rikkeid, mis kaudselt mõjustasid aluspōhja, luues tingimusi rikkevööndite arenemiseks. Neid aluspōhja rikkeid on käsitlenud A. Luha $\left.{ }^{6}\right]$, K. Orviku $\left.{ }^{8}\right]$, H. Palmre ${ }^{2}\left[{ }^{17}\right]$, K. Müürisepp $\left[{ }^{7}\right]$, K. Stumbur $\left.{ }^{17}\right]$ jt. 1959. ja 1960. aastal teostatud detailse gravimeetrilise uurimisega fikseeriti ja kontuuriti Kabala ja Sonda vahelisel maa-alal kolm aluselist intrusiooni. Need on kujutatud blokkdiagrammil. Intrusioonide pindala on $1-3 \mathrm{~km}^{2}$, nende vertikaalne ulatus $1,5-2,0 \mathrm{~km}$ Sügavamal kristalses aluskorras ühtivad nad eespool kirjeldatud suure Uljaste aluselise intrusiooniga, mida märgib lokaalne gravitatiivne struktuur. Läänepoolne intrusioon asub Uljaste järvest lääne pool, keskmine - Uljaste järvest kirde pool ja idapoolne, kōige väiksem - Sonda küla piirkonnas. Kõik kolm intrusiooni paiknevad lokaalse gravitatiivse struktuuri harjal. Vähemaid intrusioone peaks esinema veel ida pool kuni Kiviōli linnani neis kohtades, kus põlevkivilasundite uurimisel on aluspōhja kupleid avastatud. Need intrusioonid tungivad maksimaalselt kuni $100 \mathrm{mi}$ settekivimite kompleksi ja ongi pōhjustanud siinseid aluspōhja kupleid, kambriumieelse aluskorra ja settekivimite rikkeid ning rikete ja lahuste injektsiooniga kaasnevat magistumist. Siin käsitletud intrusioonid pärinevad kas silurist vōi on hilisemad.

Pōlevkivi kuplitaolised kerked Uljaste ümbruses avastas J. Reinwaldt. ${ }^{3}$ Taoliste settekompleksi rikete päritolu seoti mandrijää mõjuga. 1954. a. teostasid Uljaste piirkonna detailset magnetomeetrilist mōōdistamist E. Arro ja E. Pobul. ${ }^{4}$ Avastati rida intensiivseid magnetilisi anomaaliaid, väärtusega kuni $+2000 \mathrm{y}$, mis langesid kokku aluspõhja kuplitaoliste kergetega. Et settekompleks on praktiliselt mittemagnetiline, siis magnetiliste anomaaliate otsene seos aluspōhja kergetega kinnitas viimaste tektoonilist päritolu. Oletati magnetiliste anomaaliate järgi veel teiste, geoloogiliselt seni tundmata aluspõhja kergete esinemist Uljaste piirkonnas. Magnetiliste anomaaliate interpretatsiooni põhjal järeldas E. Pobul, et aluspōhja kerked on tingitud aluseliste intrusioonide tungimisest aluskorda. mis kutsus esile aluskorra pankade kerked (amplituudiga $75-100 \mathrm{~m}$ ) ida-lääne-suunalise regionaalse tektoonilise rikkevööndi piires. 1954. a. uuris H. Andra ${ }^{5}$ Uljaste aluspōhja kergete alasid vertikaalse elektrilise sondeerimise meetodil. Siin selgus, et ka suurematel sügavustel esinevad lasuvusrikked, mis väidavad täielikult vastu mandrijää tegevusele kergete kujunemisel.

Elektromeetrilised andmed näitavad, et otseselt kergete all esineb kambriumi sinisavi suhteline tõus $40 \mathrm{~m}$ amplituudiga.

Järgmisena uuris autor Jōhvi piirkonnas detailsemalt ida-lääne-suunalist struktuuri ja avastas võimaliku aluselise intrusiooni. Ka see intrusioon on tunginud aluskorra ja aluspōhja kontaktpinnani. Ta kujutab endast elliptilist silindrit, mille horisontaallõike ellipsi pooltelgede pikkused on $0,70 \mathrm{ja} 0,35 \mathrm{~km}$ ning pikitelje kalle horisondi suhtes $70^{\circ}$. Intrusiooni saadi jälgida gravimeetrilise meetodiga ca $3 \mathrm{~km}$ sügavuseni. Selle intrusiooni tungimine ida-lääne-suunalise Sillamäe lokaalse struktuuri kivimitesse kutsus aluskorras esile kivimite muundumist ja uute kivimite ning maakide tekkimist. Vōib oletada, et selles piirkonnas avastatud Pühajōe aluspōhja rikke tekkimist mõjustas intrusioon.

Vaivara Sinimägede piirkonnas on tegemist aluspōhja ulatusliku rikkega. Кa siin avaldus detailse gravimeetrilise meetodi efektiivsus. Mitmetel mõõteprofiilidel avastati

2 H. Pa $1 \mathrm{mre}$, Adavere lademe lühike üldine litoloogiline iseloomustus. (Käsikiri, 1960.) Х. П альм ре, Полиметаллическое орудение в доломитах адавереского горизонта в Центральной Эстонни. (Рукопись, 1959.)

3 И. Рейнв альд т, Разведка концессионной площади. (Рукопись, 1930.)

4 E. P o b u 1, Eesti NSV territooriumi magnetomeetriline uurimine. (Käsikiri, 1955.)

H. Andra, Elektrilise takistusmeetodi kasutamisest kvaternaarsete setete paksuse ja aluspōhja reljeefi tundmaōppimisel. (Käsikiri, 1955.) 
gravitatiivseid anomaaliaid, mis arvatavasti peegeldavad vähemaid aluspōhja rikkeid. Sinimägede piirkonnas avastati pindalalise mōõdistamisega anomaalia, millele. vastav struktuur lubab oletada ka siin intrusiooni esinemist. Mõõtmistulemused lubavad järeldada, et oma suurusjärgult on ta suurem kui eelmised intrusioonid. See on tüüpiline löheintrusioon, mis orienteerub läänest itta ja mille idaosa on väljaspool uuritud piirkonda.

Uuriti ka tuntud kirdesuunalist Ahtme aluspōhja riket tema lôikumiskohal lääne-ida suunalise gravimeetrilise struktuuriga. Gravimeetrilisel mõõdistamisel avastati ühes profiilis Jōhvi piirkonnas kambriumieelses aluskorras astmekujuline rike. Raske on otsustada, kas siin on tegemist aluspōhja lihtsa astmekujulise rikkega või suurema rikke nōlvaga. Uks aga on kindel: ka Ahtme aluspōhja rikke ja lokaalse gravitatiivse lääne-ida-suunalise struktuuri ristumispiirkonnas esineb kambriumieelses aluskorras rike ja magma injektsioon.

Seega on aluseliste ja happeliste intrusioonide esinemine Kirde-Eesti lääne-ida. suunalisel lokaalsel gravitatiivsel struktuuril gravimeetrilise meetodiga kindlaks tehtud Intrusioonid jälgivad struktuuri telje suunda ja asuvad piirkondades, kus nõrgad kirdesuunalised aluspôhja rikked lōikavad struktuuri. Peab märkima, et seni tehtud töö käigus ei tarvitse olla avastatud kōik vōimalikud intrusioonid, küll aga on avastatud nende leviku seaduspärasus Kirde-Eestis.

Intrusioonide esinemist Kirde-Eestis Soome lahe rannikul oletas autor juba 1953. aastal, kuid nende täpseid asukohti ja leviku suundi ei olnud tollal kasutatud gravimeetrilise sparatuuriga vōimalik veel määrata, Ka jäi lahtiseks küsimus intrusiooni seosest kirdesuunaliste aluspōhja riketega. Seda küsimust selgitati nimetatud rikete detailse gravimeetrilise uurimisega lõuna pool Uljaste-Sillamäe-Narva-Jōesuu lokaalset gravitatiivset struktuuri. Töötati välja mõōtmise metoodika, mis lubas ühe ja sama mõõdistamise käigus avastada niihästi aluskorra rikkeid kui ka nõrku aluspōhja moondeid (dolomiidistumise ja nōrga maagistumise vööndid). Uuriti laialdasel alal profiilidena Viivikonna, Jōhvi, Kiviōli, Sompa, Ratva jt. piirkondades.

See metoodika osutus efektiivseks ka kõnesoleva ülesande lahendamisel. Avastati nōrku rikkeid ja rikkevööndeid karbonaatsetes kivimites. Nende rikete raskusjōuvälja muutuse amplituud ei ületa 0,25 milligali. Mōningatel profiilidel kontrolliti gravimeetrilise uurimise tulemusi puuraukude andmetega. Puursüdamikud võimaldasid määrata rikutud karbonaatsete kivimite tihedust ja paksust, mille kaudu arvutati välja teoreetilised raskusjõu anomaaliad, mis vigade piires ühtisid môôdetud suurustega.

Lõuna pool Uljaste-Sillamäe-Narva-Jõesuu gravitatiivsete struktuuride vööndit ei avastatud gravimeetrilise meetodi abil kirdesuunaliste aluspõhja rikete all kambriumieelse aluskorra massi häireid.

Kirde-Eestis on peale Uljaste-Sillamäe-Narva-Jōesuu struktuuride vööndi veel teisigi lääne-ida-suunalisi lokaalseid gravitatiivseid struktuuride vööndeid, näit. TamsaluOonurme-Iisaku-Permisküla ja Koeru-Vägeva-Emumäe-Mustvee struktuuride vööndid.

Detailne gravimeetriline uurimine Koeru piirkonnas 9-kilomeetrisel profiilil avastas kristalse aluskorra rikke, mille suurusjärk on võrdne Uljaste läänepoolse aluskorra rikke omaga. Koeru rike ja Uljaste rikked asuvad ühel ja samal kirdesuunalisel aluspõhja rikete vööndil, millest oma töödes kirjutab H. Palmre (vt. viide 2).

Kirde-Eestis avastatud seaduspärasusi aluskorra ja aluspōhja rikete paiknemises võime üle kanda ka Kesk- ja Edela-Eesti alale

Kesk-Eestit läbib tugev lääne-ida-suunaliste lokaalsete gravitatiivsete struktuuride vöönd, mis on analoogiline Uljaste-Sillamäe-Narva-Jõesuu struktuuriga, kuid palju tugevamini välja arenenud. See vöönd koosneb Lōppe, Koonga, Pärnu-Jaagupi, Tootsi, Võhma, Pōltsamaa ja Kaatvere struktuuridest (vt. kaardid 1 ja 2). Kohtades, kus see vöönd lōikub kirdesuunaliste aluspōhja riketega, peaksid asetsema intrusioonid, nendega kaasnevad rikked ning vőimaliku maagistumise piirkonnad. Uht sellist, oma pōhjaosas äsja kirjeldatud aluspōhja kirdesuunalist riket, nimelt seda, mis läbib Uljaste, VäikeMaarja, Koeru, Vōhma, Viljandi ja Ikla lokaalsed gravitatiivsed struktuurid, vōimaldavad jälgida olemasolevad lokaalsed gravitatiivsed struktuurid. Rikke täpsemat kulgu saab 
määrata 1959. ja 1960. a. välja töötatud metoodika alusel detailsete gravimeetriliste mōōdistamistega.

Need oleksid lühidalt gravimeetrilise uurimistöö tulemused Kirde-Eestis, Sellest fakti. lisest materjalist tuleks edaspidi lähtuda nii Kirde-Eesti kui ka kogu vabariigi geofüüsikaliste tööde teostamisel, millede eesmärgiks on kirdesuunaliste rikete uurimine seoses maakide otsinguga.

Eesti NSV gravitatiivsete struktuuride tôlgendust takistas varematel aastatel eelarvamus, nagu ei esineks rabakivigraniitide massiivides nooremaid intrusioone. Need väärad tōekspidamised on kummutatud. Nii on Ahvenamaa saarestikus avastatud nn. Äva happeline intrusioon, mis üldjoontes on ringikujuline ja 3 -kilomeetrise raadiusega $\left.{ }^{3}\right]$. On isegi avastatud rabakiviformatsiooniga seoses esinevaid pegmatiite. Seega võib pidada tõenäoliseks, et Kirde-Eestis toimusid kunagi analoogilised protsessid, mis kujundasid siinset aluskorda.

Mainisime juba, et rabakivi intrusioonid kujundasid ümber ka Kirde-Eesti kristalse aluskorra. Need intrusioonid mōjustasid oma temperatuuriga kontaktpindade kivimeid vảya nōrgalt, kuid seda tugevam oli nende lōhestav tegevus naaberaladel. Samasugused rikkeja purustusvööndid asuvadki Rakvere ja Narva vahelisel alal, mis veel pikaks ajaks jäid tektooniliselt aktiivseks. Hilisemad tektoonilised protsessid leidsid vastukaja rikutud vööndites ja neis aktiviseerus magma liikumine. Taolised hilisemad protsessid pōhjustasid kirdesuunalisi aluskorra ja aluspõhja rikkeid. Kohtadel, kus sellised rikked ristusid vanade purustustsoonidega, antud juhul Uljaste-Sillamäe-Narva-Jōesuu gravitatiivsete struktuuride vööndiga, aktiviseerus lōhedes injektsioon ja tekkisid tüüpilised väikesed intrusioonid, milledest oli juba eespool juttu.

Kirdesuunalised, nooremad rikked vôisid tekkida Kaledoonia orogeneesi käigus. Ent see pole kaugeltki ainuke vōimalik oletus. On veel teine, samuti oletatav põhjus, mis kerkis esile, kui autor töötas läbi Eesti NSV ja teda ümbritsevate alade gravimeetrilisi anomaaliaid ja sidus neid Fennoskandia tōusuga. Maakoore vertikaalse tōusu tsenter paikneb antud juhul Põhja lahel Merenkurkku piirkonnas. See tōus on fikseeritud täpsete loodimistega nii Soome kui ka Eesti territooriumil. Gravitatiivsete anomaaliate läbitöötamine näitas, et maakoor ei ole tõusnud ladusa kuplina, vaid omab astmelist kuju. Siit vôib järeldada, et maakoorde kuhjusid tôusu tulemusena pinged, mis aeg-ajalt lahenesid, pōhjustades väikesi lōhesid ja maakoore üksikute pangaste nihkeid. Maakoore vertikaaltōusust tingitud rikked peaksid arenema tangentsiaalselt, mööda puutujat, sest antud juhul sisemistest jōududest esilekutsutud pinged jaotuvad kontsentrilistel ringidel. $\mathrm{E}_{\mathrm{i}}$ ole ka vōimatu radiaalsete rikete esinemine, kuid nende esinemise tōenäosus on palju väiksem.

Nagu näitavad Soome geoloogide P. Eskola [ $\left.{ }^{1}\right]$, V. Hackmani $\left[{ }^{2}\right]$, A. Laitakari [ $\left.{ }^{4}\right]$, H. Renqvisti [ $\left.{ }^{9}\right]$, H. Väyryneni $\left[{ }^{13}\right]$ jt. uurimused, esineb sealses kristalses aluskorras nooremaid, postsiluri intrusioone, mistōttu võib järeldada, et meie avastatud Kirde-Eesti siluri intrusioonid pole mingi erand, vaid vanade Svekofenniidide ala seaduspärane nähtus.

Ka kvaternaarsete setete kuhjumisele on Kirde-Eestis toimunud tektoonilised protsessid avaldanud oma mõju. Nende protsessidega lōhestatud ja tõstetud karbonaatsete kivimite piirkonnad suutsid mannerjää purustavale toimele avaldada vähemat vastupanu kui rikkumata alad. See selgitab ka Sinimägede teket. Eesti geoloogid $\left.{ }^{[}{ }^{8}\right]$ kinnitasid juba ammu, et Vaivara Sinimäed on jääaja pärand, mandrijää töö. Sama seisukohta kinnitavad ka detailsed gravimeetrilised mõōtmised, mis avastasid selles piirkonnas happelise intrusiooni. Viimasega kaasnesid lõhestused, purustused ja üksikute settekivimite pankade kerked, mis lōidki soodsa pinna mandrijää purustavale toimele. Oksikuist piirkondadest kanti ära lahtikistud settekivimite pangad ja kuhjati need teisale. Samasse liiki kuulub ka Pühajõe settekivimite rike, mille kohal asub kambriumieelses aluskorras Jōhvi intrusioon. Nüüd on ka selge, miks mandrijää purustas just näiteks Vaivara piirkonda ja miks aluskorra rike asub Pühajōe piirkonnas.

Tähendab - jää tegevus, vähemalt eespool käsitletud piirkondades, on sekundaarne protsess. Primaarsena aga esinevad kambriumieelses aluskorras asetleidnud tektoonilised protsessid. 


\section{K I R J A N D S}

1. P. Eskola, Volcanic Necks in Lake Jänisjärvi in Eastern Finland, Bull. Comm. Géol. de Finlande, Nr. 55, Helsinki, 1921.

2. V. $\mathrm{H} \mathrm{a} \mathrm{ckm}$ a n, Neue Mitteilungen über das Ijolithmassiv in Kuusamo, Bull. Comm. Géol. de Finlande, Nr. 11, Helsinki, 1914.

3. S. Ka it a ro, Geologic Structure of the Late Pre-Cambrian Intrusive in the Ava Arear Alland Islands, Bull. Comm. Géol. de Finlande, Nr. 162, Helsinki, 1953.

4. A. La it a kari, Suomen Geologien Yleiskartta, Lehti B 3, Vaasa, kivilajikartan selitys, Geol. toimik., 1942.

5. A. Li n a ri, Aruanne sügavpuurimistest Jōhvi lähedal, Tallinna Tehnikaülikooli Toimetused, 1940, nr. 15 .

6. A. L u h a, Eesti NSV maavarad, Tallinn, 1946.

7. K. $M$ üüri isep p, Aseri lasumusrikkest, Eesti Geograafia Seltsi Aastaraamat 1960 , Tallinn, 1961.

8. K. O r viku, Rändpangased Eestis, Loodusuurijate Seltsi aruanded, kd, 33, 1926

9. H. Renquist, Finlands jordskalv, Deutsch. Ref. Erdbeben in Finland, Fennia, 54, Nr. 1, 1930.

10. M. S a ksela, Das pyroklastische Gestein von Lappajärvi und seine Verbreitung als Geschiebe, Bull. Comm. Géol. de Finlande, Nr. 144, 1949.

11. J. S e de rh o $1 \mathrm{~m}$, Pre-Quaternary Rocks of Finland, Bull. Comm. Géol. de Finlande. Nr. 91,1930

12. H. V. Tu ominen, The Structural of an Archean Area Orijärvi, Finland, Helsinki, 1957.

13. H. Vä у г улп еn, Suomen kallioperä sen synty ja geologinen Kehitys, Helsinki, 1954.

14. A. Ö p ik, Eine mögliche geologische Deutung der magnetischen Anomalien Estlands, Verhandlung abgehaltenen achten Tagung der Baltischen Geodätischen Kommission, Helsinki, 1936.

15. В. Бе ло усов, Основные вопросы геотектоннки, Москва, 1954.

16. Х. П альмре, Закономерности полиметаллического оруденения на территории Эстонской ССР, Закономерности размешення месторождений в платформенных чехлах, ч. ІІ, Кнев, 1960.

17. К. А. С ту м бу р, О новых данных по тектоническим нарушениям, Информашионный бюллетень (Управленне геологии и охраны недр при СМ ЭССР). № 1,1959

Eesti NSV Teaduste Akadeemia Geoloogia Instituut
Saabus toimetusse

1. IV 1961

\section{ДЕТАЛЬНЫЕ ИССЛЕДОВАНИЯ СТРУКТУР КРИСТАЛЛИЧЕСКОГО ФУНДАМЕНТА И КОРЕННЫХ ПОРОД СЕВЕРО-ВОСТОЧНОИ ЭСТОНИИ ГРАВИМЕТРИЧЕСКИМ МЕТОДОМ}

\section{В. Маазик,}

кандидат физико-математических наук

\section{Резюме}

В Институте геологии АН ЭССР разработана методика гравиметрических исследований, при которой нспользуется гравиметр высокой точности $(0,02$ миллигал). C помөщью этой методики в северо-восточной Эстонии удалось уточнить структуры, выявленные обычным гравиметрическим методом, и дополнительно выявить детальные структуры.

В 1953 г. гравиметрическим методом обследована так называемая зона структур Ульясте-Силламяэ-Нарва-Иыэсуу, проходящая вдоль южного побережья Финского залива. Эта зона структур представляет собой массив граннтов и гнейсов, в котором- связи с интрузиями гранита рапакиви наблюдаются сильные нарушения н инъекции (в районе Выборга, Раквере и Аландских островов). Описываемая зона сставалась тектонически актнвной в течение очень длительного времени.

В 1959-1960 гг. на западно-восточном простнранни названной структуры гравнметрическими исследованиями открыт целый ряд основных и одна кнслая интрузии, некоторые из которых проходят на глубину до 100 м в осадочные породы, нарушив их и вызвав прнметы рудопроявления. Эти интрузнн располагаются в местах, где 
позднее нарушения коренных пород северо-восточного простирания врезаются в прежнюю структуру западно-восточного простирания. Нарушения северо-восточного простирания образовались либо в каледонском орогенезисе, либо в результате напряжений, которые нагромождались в земной коре вследствие поднятия Фенноскандии.

Можно предполагать, что там, где эти нарушения северо-восточного простирания скрециваются с гравитационными структурами западно-восточного простирания также встречаются аналогичные нарушення и интрузии. То же самое можно предполагать и относительно центральной Эстонин.

В коренных породах, залегающих в зонах нарушений северо-восточного простирания, местами можно заметить слабое оруденение (Вийвиконна). Но в кристаллическом фундаменте гравиметрическим методом нарущения и инъекции не обнаружены В то же время там, где нарушения коренных пород северо-восточного простирания врезаются в гравиметрические структуры западно-восточного простирания, встречаются более сильные нарушения как в коренных породах, так и в кристаллическом фундаменте; кроме того, здесь встречаются интрузии, сопровождающие их нарушения и возможные оруденения.

На основе изложенных данных создана теоретическая основа для дальнейших понсков руд в районе нарушений коренных пород северо-восточного простирания в северо-восточной и центральной Эстонии.

Ннститут геологии

Академии наук Эстонской ССР
Поступила в редакцию

1. IV 1961

\section{DETAILED INVESTIGATIONS BY GRAVIMETRIC METHODS OF NORTHEAST ESTONIAN STRUCTURES OF CRYSTALLINE BASE AND BEDROCK}

\section{Maasik}

\section{Summary}

At the Institute of Geology of the Estonian S.S.R. methods of gravimetric investigations have been elaborated, at which a high-precision gravimetre (0.02 milligal) is used. With the help of these methods it has been possible to determine, in the northeastern part of Estonia, structures that can be determined by usual gravimetric methods and, in addition, to define detailed structures.

In 1953 the so-called zone of structures Uljaste-Sillamäe-Narva-Jōesuu stretching along the south coast of the Gulf of Finland was investigated by gravimetric methods. This zone is represented by a massif of granites and gneisses in which, in connection with intrusions of Rapakivi granite, considerable destructions and injections (in the districts of Viipuri, Rakvere, and the Âland Isles) occur. This zone was tectonically active during a very long period.

In 1959-1960 in the west-eastern stretching of the structure quite a large number of basic intrusions and an acid one were detected by gravimetric methods, some of these intrusions attaining a depth of $100 \mathrm{~m}$ in the basic rock, destructing it and calling forth phenomena of orogenesis. These intrusions are distributed at places where, later on, cracks in the basic rock of north-western stretching cut into the former structure of westeastern stretching. The cracks of the north-eastern direction were formed either during the Caledonian orogenesis, or as a result of the tension which accumulated in the earth's crust owing to the uplift of Fennoscandia.

It may be supposed that at places where the cracks of north-eastern stretching cross the gravitational structures of the west-eastern stretching, there are also analogous destructions in the intrusion. The same fact may be assumed concerning Central Estonia.

In the basic rocks distributed in the zones of destruction of north-eastern stretching, weak orogenesis may be observed in places (Viivikonna).

It has not, however, been possible to detect any destructions or injections in the crystalline base by gravimetric methods. On the other hand, in places where the destructions of the bedrock of north-eastern direction cut into the gravimetric structures of westeastern direction, more considerable destructions both in the basic rock and in the crystalline base may be observed; here, moreover, intrusions are met, accompanied by destruction and probable orogenesis.

On the grounds of the data received, a theoretical basis has been established for a further detection of ores in the zone of destructed basic rocks of north-eastern stretching in Northeast and Central Estonia.

\section{Academy of Sciences of the Estonian S.S.R., Institute of Geology}

Received April 1st, 1961 